\title{
Design and Optimisation of Home Scale Greywater Recycling Package
}

\author{
Kalaichelvan a/1 Arugam ${ }^{1}$, Azadeh Ghadimi ${ }^{1, *}$, and LH Chang $^{2}$ \\ ${ }^{1}$ Department of Mechanical Engineering, Taylor's University, Malaysia \\ ${ }^{2}$ DD Techniche Sdn. Bhd., No. 11-3, Jalan USJ 21/1, UEP Subang Jaya, Selangor, 47630 \\ Subang Jaya, Malaysia
}

\begin{abstract}
Water crisis is becoming one of the biggest challenges in some countries due to over population and drought. Therefore, government and non-government organisations in well-developed countries are encouraging industries to install water recycling package to reduce water usage and consume greywater instead. However the home scale is not yet available in the market. This research focuses on design a home scale greywater treatment system for toilet flushing within 3,000 to 5,000 USD as a collaboration with DD Techniche Sdn Bhd. Greywater is the waste water produced from laundry, kitchen and bathroom except the toilet waste and contains suspended solids, microorganisms, oil, nitrates and phosphorus which needs to be treated using suitable types of treatment for safe reuse. The treatments include physical, chemical and biological water treatment in which in this study the proposed system is a combination of all three. The design is evaluated using experimental methods to meet the standard of toilet flushing quality. The greywater system consists of the mechanical parts to control the flow of greywater and store the treated water including pumps, sand filtration tank, wire mesh chassis and collection tank. The final design has dimension of $6 \mathrm{~m} 3$ and optimised price within the budget.
\end{abstract}

\section{Introduction}

Water crisis is becoming one of the biggest threat in some countries. Especially, countries in Middle East are facing severe water crisis due to drought. Countries with high population also face water crisis due to high water usage [1]. Water crisis can be reduced by controlling the water usage. One of the successful method to control water usage is by recycling rain water and greywater. Government and non-government organisations are encouraging industries to have water recycling system to reduce water crisis. DD Techniche Sdn Bhd is a water recycling package Installer Company has seen the potential to market a home scale greywater treatment for toilet flushing within the budget ranging between 3,000 USD to 5,000 USD.

\footnotetext{
${ }^{1}$ Corresponding author: Azadeh.Ghadimi@taylors.edu.my
} 
The company has come out with this initiative due the attention gained by the industrial scale greywater treatment package and the absence of home scale greywater treatment system. Greywater is the water produced from the laundry, kitchen and toilet except the toilet wastes [2]. Greywater contains phosphorus and nitrates due to the usage of detergent, shampoo and dishwasher liquid [3]. Greywater also contains bacteria, total suspended solids, oil and grease. The total suspended solids (TSS) are hair from the bathroom, dirt from laundry and food particles from kitchen. These contents in the greywater causes infection to the user if not treated. Therefore, the greywater must be treated before reusing it for toilet flushing.

There are three types of treatment, which are the physical treatment, chemical treatment and biological treatment. Physical treatment involves filtering out particles from water based on the size using wire mesh or membrane [4]. This treatment is applicable to filter the suspended solid and reduce the turbidity. Chemical treatment is process of adding chemicals into the water to neutralise the bacteria through salt addition [5]. Chemical treatment also involves coagulation process. Coagulation is the process of accumulating the bacteria together to increase the size and filter out using the physical treatment [2]. Biological treatment is microbial reaction using microorganism to convert bacteria into gas, water and biomass [6].

Greywater treatment must consist at least two types of treatment because chemical or biological treatment can treat bacteria but need to be supported by the physical treatment to filter the solid particles. The design of greywater treatment package for this project requires to have dimension of $2 \mathrm{~m} \times 2 \mathrm{~m} \times 2 \mathrm{~m}$ and budget within 3,000 USD and 5,000 USD. The design for this project is be inspired from the existing industrial scale water recycling system. The existing industrial designs for greywater recycling system are slow sand filtration, membrane bioreactor and water treatment with clarifiers.

The final design of greywater treatment package for this project is made up of pretreatment stage with wire mesh and followed by slow sand filtration. This design consists all three types of water treatment stated above. The pre-treatment with wire mesh involves physical treatment to filter out food particles, hair and other suspended solids. The slow sand filtration involves physical treatment, biological treatment and chemical treatment. The water is accumulated at the top of sand to form platform for biological treatment. Then, the water passes through the sand and the waste from the biological treatment is filtered out by the sand layer. The nitrates in the water are be treated through denitrification by the sand layer.

The greywater treatment package consists of mechanical parts to control the flow and store the greywater for toilet flushing. The mechanical parts are pumps, sand filtration tank, wire mesh chassis and collection tank. The mechanical parts are designed based on the flow rate of the greywater. The pumps are used to pump the water from the collection tank to storage tank at the roof top for distribution. The sand filtration tank is designed based on the flow rate entering the sand filtration and requirement of sand height by the environmental organisations. Wire mesh are designed based on the size of particles to be filtered out and budget.

The design is evaluated by comparing the treated water with standard water quality for toilet flushing. The system must be able to meet the water quality for toilet flushing. The water quality is compared by measuring the total suspended solid (TSS), chemical oxygen demand (COD) and turbidity. These three parameters must meet the standard water quality for toilet flushing. The final design is represented in 3D model with all the mechanical parts.

The objectives of this project are to design a home scale greywater recycling package and optimise the design by having low cost compare to existing designs in the market. The final design is able to treat the greywater for toilet flushing. The design is optimised by having lower cost than existing home scale greywater package. 
This project creates the chance for the public to use the greywater treatment system for household. These reduces the water usage for the public, which will reduce the cost if the system is used for long term. Reducing water usage results in reduction of water crisis. This system able to gradually bring advantage to the economy and environment. Since, public are not using any water recycling system currently because water recycling systems are only manufactured in industrial scale, this project able to fulfil the gap of designing a home scale water recycling system.

\section{Methodology}

This project involves designing, 3D modelling, prototyping and experimental evaluation. The designing involves the designing of pre-treatment stage with wire mesh, slow sand filtration and pump. The design is modelled into 3D prototype using SolidWorks Ver. 2016. The performance of the design is evaluated using the prototype.

\subsection{Designing Stage}

The greywater treatment system consists of pre-treatment filter, slow sand filtration, pump, and collection tank. The greywater enters to the pre-treatment filter and follow by the slow sand filtration. The treated water is collected in the collection tank. Then, the treated water is pumped to the storage tank using the auto water pump. The treated water is distributed to the toilets from storage tank.

The pre-treatment filter consists coarse and fine wire mesh. The pore size of coarse wire mesh is $1 \mathrm{~mm}$ and the pore size for the fine wire mesh is $0.5 \mathrm{~mm}$. The coarse mesh is used to filter out hairs and particles that are larger than $1 \mathrm{~mm}$. The fine mesh is used to filter out dirt and particles larger than $0.5 \mathrm{~mm}$. The pre-treatment stage is designed vertically to use the gravitational force during the filtration. The gravitational force provides extra support to push the water through the pores of the wire mesh. The wire mesh is designed to have hemispherical surface to provide larger filtration area. The hemispherical shape also provides the slippery slope for the movement of filtered particles through the drainage pipe.

The slow sand filtration consists sand layer and gravel. The slow water flows on the sand causes the water to accumulate at the top to form water bed for the biological treatment [7]. The biological treatment transforms bacteria into gas, water and biomass. The biomass is filtered by the pores between the sand. The sand also involves chemical treatment. The sand neutralises the nitrates through denitrifications [8].

The slow sand filtration is designed based on the volumetric flow rate equations and requirement by the environmental organisation [8]. Volumetric flow rate equation is applied to calculate the filtration area of the sand. Volumetric flow rate means the volume of water passes through medium per unit time. The volumetric flow rate equation is shown below.

$$
\mathrm{A}=\frac{Q}{v}
$$

Where, $A=$ surface area of the sand filter $\left(\mathrm{m}^{2}\right)$

$\mathrm{Q}=$ flow rate onto the filter surface $(\mathrm{L} / \mathrm{h})$

$\mathrm{V}=$ loading rate of sand $\left(\mathrm{L} / \mathrm{hm}^{2}\right)$

The flow rate of greywater in household are obtained from the journal published by the Texas A\&M University from United States [9]. The data are shown in Table 2. The loading rate is set at $400 \mathrm{~L} / \mathrm{hm} 2$ because it is the optimum loading rate for sand filtration based on the environmental organisations from United States and United Kingdom. Therefore, the surface area of the sand filter can be calculated by substituting the parameters. 
The height of sand filtration and gravel are designed based on the standard dimension set by the environmental organisation from well-developed country. This dimensions are set by the organisations based on the feedbacks gathered from the existing slow sand filtration. The dimensions are listed in Table 3.

Table 1. Parameters for sand filtrations system $[7,10]$

\begin{tabular}{|c|c|c|}
\hline Organisations & Parameters & Dimensions \\
\hline \multirow{3}{*}{ Cisco Foundations } & Sand depth & $\geq 50 \mathrm{~cm}$ \\
\cline { 2 - 3 } & Loading rate & $400 \mathrm{~L} / \mathrm{hm}^{2}$ \\
\cline { 2 - 3 } & Gravel Depth & $\geq 5 \mathrm{~cm}$ \\
\hline American Water Works Association & Sand Depth & $\geq 50 \mathrm{~cm}$ \\
\cline { 2 - 3 } & Loading rate & $100 \mathrm{~L} / \mathrm{hm}^{2}-400 \mathrm{~L} / \mathrm{hm}^{2}$ \\
\hline
\end{tabular}

Based on requirement in Table 1, the height of sand is set to $50 \mathrm{~cm}$ and the height is validated by applying Darcy's law. Darcy's law is used to calculate the flow rate of liquid that passes through a porous medium. Darcy's law states that the water flows from high potential area to low potential area. Therefore, the water in the sand filter obeys this law where, the water on top flows to the bottom due to the potential difference. Darcy's equation (2) is given as shown below. The sand depth recommended by environmental body is validated using the Darcy's law.

$$
\mathrm{Q}_{\max }=\mathrm{k} \cdot \mathrm{A} \cdot \frac{h+d}{d}
$$

Where, $\mathrm{Q}_{\max }=$ Maximum flow rate $\left(\mathrm{m}^{3} / \mathrm{s}\right)$

$\mathrm{k}=$ Hydraulic conductivity of sand $(\mathrm{m} / \mathrm{s})$

$\mathrm{h}=$ Depth of clearance above the sand $(\mathrm{m})$

$\mathrm{d}=$ Depth of sand $(\mathrm{m})$

The designing of pump includes the process of transferring the water from collection tank at the slow sand filtration to the storage tank. Auto water pump is used in this project because the slow sand filtration required longer time to fill in the collection tank. The pump should operate once the collection tank is full. Auto water pump activates based on the water level. Therefore, auto water pump is the ideal choice for this project.

The suitable pump can be chosen based on the water horsepower. The parameters that are related in the horsepower pump designing is the head loss and water flow rate. The equation relating these parameters are shown below. Head loss is the distance to pump the water from one point to another point. The pump for this project must be able to transfer the water from the collection tank to storage tank at the rooftop. Therefore, the head loss is the height of the house, which is generally $5.7 \mathrm{~m}$.

$$
\mathrm{WHP}=\frac{Q \times H}{3960}
$$

Where, WHP= Water horsepower (hp)

$\mathrm{Q}=$ flow rate of water from the pump (gallon/minute)

$\mathrm{H}=$ head loss or distance to pump the water (foot)

\subsection{D Modelling}

The design of the pre-treatment stage and slow sand filtration are modelled as software prototype using SolidWorks Ver. 2017. The pre-treatment stage consists of three parts, which are the mesh holder, filtration chassis and chassis connector. The mesh holder is placed in the filtration chassis and the coarse filtration chassis is connected to the fine filtration chassis using the chassis connector. Since, 4 inches PVC pipe commonly used as 
greywater outlet, the pre-treatment stage is designed to have same dimension as 4 inches PVC pipe for ease of installation. The drawing of mesh holder is shown in Figure 1.

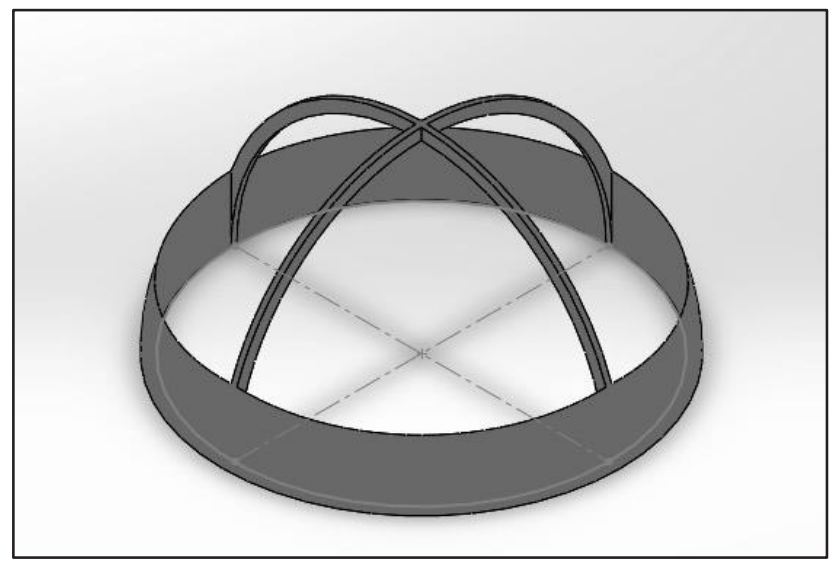

Fig. 1. Mesh holder

The slow sand filtration chassis was designed based on the calculations carried out using the equations and requirements as discussed in Section 2.1. The slow sand filtration consists two parts which are the chassis and connector. The chassis is used to fill the sand and gravel. The connecter is used to connect the sand filtration to the pre-treatment stage. The complete 3D model is shown in Figure 2.

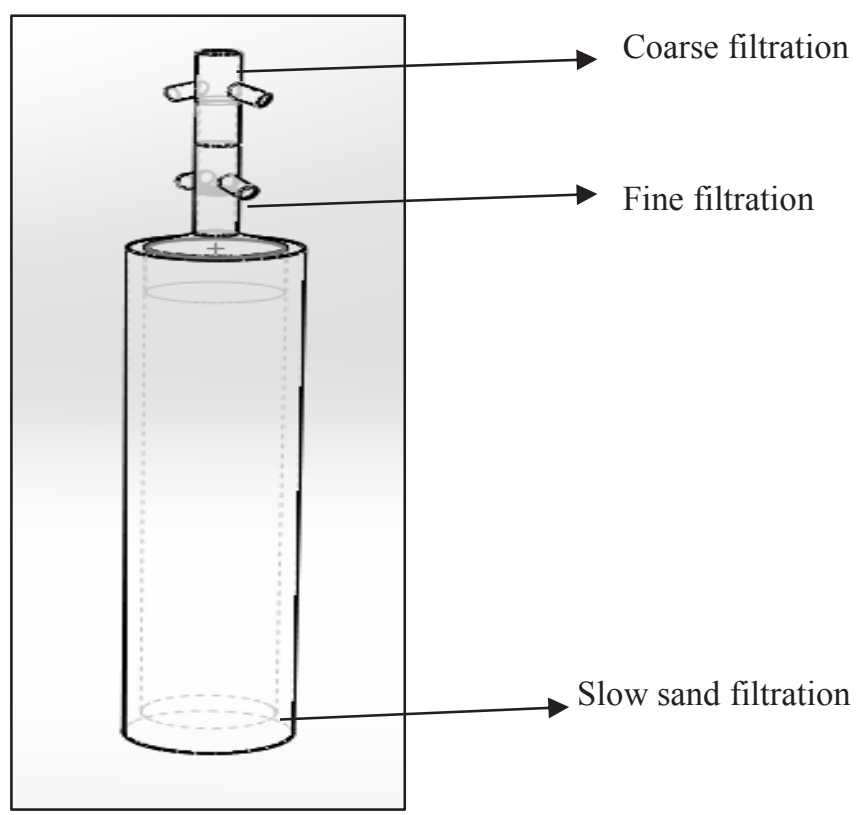

Fig. 2. Drawing of the whole filtration system 


\subsection{Prototyping}

The prototyping stage involves the manufacturing of the pre-treatment filter and the sand filtration to evaluate the design. The pre-treatment filter is built using the $110 \mathrm{~mm}$ PVC pipe with PVC pipe connector. The wire mesh for fine screening and coarse screening are glued in the pipe using adhesive bonding. The complete prototype model for pre-treatment filter is shown Figure 3.

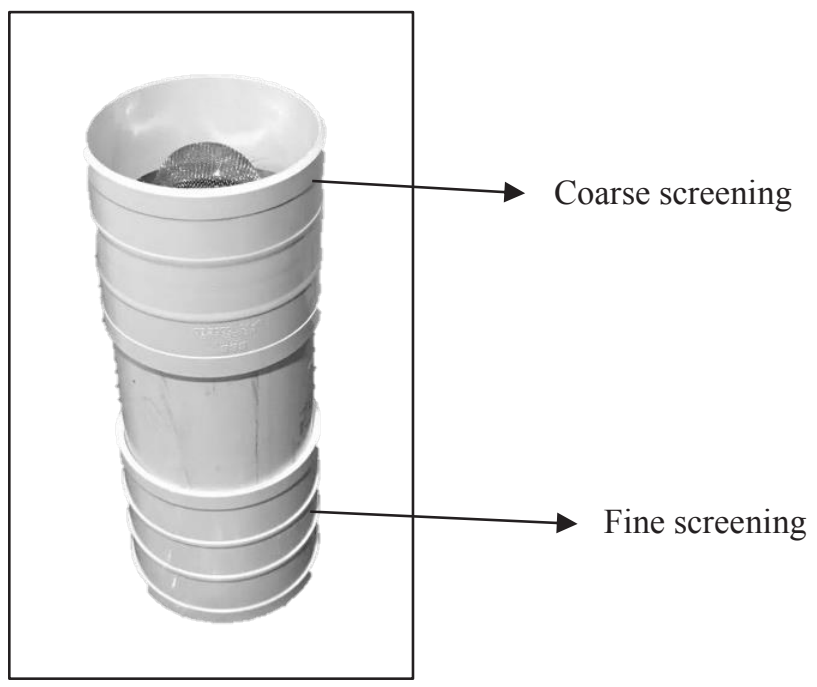

Fig. 3. Pre-treatment filter

The slow sand filtration is manufactured using plastic tanks. The slow sand filtration is manufactured in scaled down dimension because the prototype is only needed to evaluate whether the system can treat the greywater to meet standard quality of water for toilet flushing. The prototypes are manufactured for use of experiments to evaluate the design.

\subsection{Experiments}

The project involves the experiments to measure the flow rate entering the sand filter from the pre-treatment stage, total suspended solid (TSS), chemical oxygen demand (COD) and turbidity. The TSS, COD and turbidity is measured to evaluate whether the treated water meets the standard water quality for toilet flushing. The standard water quality for toilet flushing is gathered from various water quality department as shown in Table 2. The performance of the design is evaluated by comparing the treated water with parameters in Table 2.

Table 2. Water quality for toilet flushing based on American standards

\begin{tabular}{|c|c|c|}
\hline Organisation & Parameter & Value \\
\hline \multirow{3}{*}{ United States Environmental } & BOD & $\leq 10 \mathrm{mg} / \mathrm{L}$ \\
\cline { 2 - 3 } Protection Agency (US EPA) [1] & COD & - \\
\cline { 2 - 3 } & Turbidity & $\leq 2 \mathrm{NTU}$ \\
\cline { 2 - 3 } & TSS & - \\
\hline
\end{tabular}




\begin{tabular}{|c|c|c|}
\hline \multirow{4}{*}{ World Health Organization [12] } & BOD & $\leq 10 \mathrm{mg} / \mathrm{L}$ \\
\cline { 2 - 3 } & COD & - \\
\cline { 2 - 3 } & Turbidity & - \\
\cline { 2 - 3 } & TSS & $\leq 10 \mathrm{mg} / \mathrm{L}$ \\
\hline \multirow{4}{*}{ Canada Health Department [13] } & BOD & $\leq 10 \mathrm{mg} / \mathrm{L}$ \\
\cline { 2 - 3 } & COD & - \\
\cline { 2 - 3 } & Turbidity & $\leq 2 \mathrm{NTU}$ \\
\cline { 2 - 3 } $\begin{array}{c}\text { The International Water Quality } \\
\text { published book titled Milestone in } \\
\text { Water Reuse [14] }\end{array}$ & TSS & - \\
\cline { 2 - 3 } & BOD & $\leq 30 \mathrm{mg} / \mathrm{L}$ \\
\cline { 2 - 3 } & COD & - \\
\cline { 2 - 3 } & TSS & - \\
\hline
\end{tabular}

\subsubsection{Flow Rate Test}

The objective of this experiment is to determine the flow out rate of the greywater from the pre-treatment stage. Flow out rate is needed to calculate the surface area for the slow sand filtration. The experiment is conducted to obtain the relationship between the flow in and flow out of the pre-treatment system. The relationship can be used to approximately measure the flow out rate at any particular flow in rate for the pre-treatment stage.

The experiment is conducted by measuring the flow in rate from tap water by adjusting the tap at different angle. The time taken to fill $2 \mathrm{~L}$ of water at each angle is recorded. The procedures are repeated by passing the tap water through the pre-treatment filter. The time taken to fill $2 \mathrm{~L}$ of water with the presence of pre-treatment filter represents the flow out rate and the time taken to fill $2 \mathrm{~L}$ of water with the absence of pre-treatment filter represents the flow in rate. The graph of flow out rate against flow in rate is plotted and the relationship is obtained. Based on the relationship, the flow out rate is substituted into equation 1 to calculate the surface area for sand filtration.

\subsubsection{Turbidity Experiment}

The turbidity of the treated water is measured using the turbidity tube. Turbidity tube is measuring cylinder with a reference disk at the bottom of the tube as an indicator. The treated water is filled up until the maximum level, where the reference plane is still visible as shown in Figure 4. Then, the height of the water level in the cylinder is measured. The height is converted into turbidity scale using the table obtained from lab manual prepared by Chicago River Schools Network [15]. 


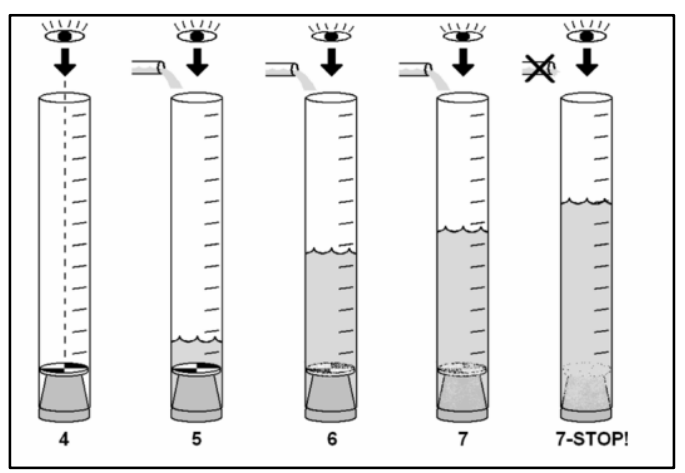

Fig. 4. Filling the treated water until the maximum level, where the disk is visible

\subsubsection{Chemical Oxygen Demand Experiment}

Chemical oxygen demand, COD is the total oxygen consumption by all the organic substances in the water [16]. High values of COD indicate the water has high level of microorganisms and pollution [17]. The COD experiments is carried out by adding nitric acid into the treated water. Then, the mixture is heated until the oxidation process completed and the remaining unreacted nitric acid is weighed. The mass of reacted nitric acid is calculated by subtracting the remaining unreacted nitric acid added to the treated water. The mass of dissolved nitric acid represents the COD of the treated water in $\mathrm{g} / \mathrm{L}$.

\subsubsection{Total Suspended Solid Experiment}

Total suspended solid (TSS) is the quantity of solid particles in the water. The TSS experiment involves the evaporation of the treated water. $1 \mathrm{~L}$ of treated water is evaporated under the sun and leftover residue after evaporation is weighed. The mass of leftover residue represents the TSS value in $\mathrm{g} / \mathrm{L}$.

\subsection{Limitation}

Limitation in this project is the usage of instruments for the measurement of COD, TSS and turbidity of the water. The COD, TSS and turbidity of the water are measured using manual experimental method. The instruments are not used because budgets or facility to borrow the instruments are not allocated by the industry supervisor. Therefore, the manual methods of determining this parameter involve limitation such as the scale and sensitivity. The turbidity test only able to give minimum value of 5 NTU.

\section{Results and Discussion}

The data of time taken to fill $2 \mathrm{~L}$ of water with the absence of pre-treatment filter is tabulated as shown in Table 3. Table 3 shows the flow in rate when the tap is at different angle. Table 4 represents the time taken to fill $2 \mathrm{~L}$ of water with the presence of pretreatment filter. The graph of flow out rate against flow in rate is plotted as shown in Figure 7.

Table 3. Results of flow in rate 


\begin{tabular}{|c|c|c|c|c|}
\hline \multirow{2}{*}{$\begin{array}{c}\text { Tap angle } \\
\left({ }^{\circ}\right)\end{array}$} & \multicolumn{3}{|c|}{ Time Taken to fill 2 L (s) } & \multirow{2}{*}{ Flow in rate (L/s) } \\
\cline { 2 - 4 } & $\mathbf{1 s t}$ & 2nd & Average & 0 \\
\hline 45 & 0 & 0 & 0 & 0.0194 \\
\hline 90 & 101.42 & 105.2 & 103.31 & 0.0764 \\
\hline 135 & 26.13 & 26.22 & 26.18 & 0.0786 \\
\hline 270 & 25.35 & 25.53 & 25.44 & 0.0808 \\
\hline 360 & 25.12 & 24.37 & 24.75 & 0.0821 \\
\hline 405 & 25.24 & 23.51 & 24.375 & 0.0844 \\
\hline 450 & 23.16 & 24.25 & 23.71 & 0.0878 \\
\hline 495 & 21.68 & 23.88 & 22.78 & \\
\hline
\end{tabular}

Table 4. Results of flow out rate

\begin{tabular}{|c|c|c|c|c|}
\hline \multirow{2}{*}{$\begin{array}{c}\text { Tap angle } \\
(\boldsymbol{(})\end{array}$} & \multicolumn{3}{|c|}{ Time Taken to fill 2 L with Filter (s) } & \multirow{2}{*}{ Flow out rate (L/s) } \\
\cline { 2 - 4 } & $\mathbf{1 s t}$ & 2nd & Average & 0 \\
\hline 45 & 0 & 0 & 0 & 0.019 \\
\hline 90 & 107.37 & 105.92 & 106.645 & 0.0689 \\
\hline 135 & 29.18 & 28.87 & 29.03 & 0.0760 \\
\hline 270 & 27.08 & 25.54 & 26.31 & 0.0784 \\
\hline 360 & 27.68 & 23.33 & 25.51 & 0.078 \\
\hline 405 & 25.63 & 25.48 & 25.555 & 0.0786 \\
\hline 450 & 27.33 & 23.55 & 25.44 & 0.0836 \\
\hline 495 & 24.7 & 23.16 & 23.93 & \\
\hline
\end{tabular}

Graph in Figure 5 represents the relationship between the flow in rate and flow out rate. The relationship equation is obtained to calculate the flow entering the slow sand filtration. The flow out rate is represented as $\mathrm{y}$ and the flow in rate is represented as $\mathrm{x}$. The flow out rate represents the flow rate entering the slow sand filtration. Then, the surface area required for the slow sand filtration is calculated using equation 1 and tabulated in Table 5. Therefore, the slow sand filtration is designed based on the calculated surface area as shown in Table 5. The sand filtration surface has $21 \mathrm{~cm}$ of radius. Therefore, the design can be used up to maximum of 4-bedroom house. Based on Table 5, the maximum flow rate entering the slow sand filtration is $54.76 \mathrm{~L} / \mathrm{h}$. Therefore, the maximum flow rate can be handled by the slow sand filtration can be calculated using the Darcy's equation as shown below. The sand depth, $\mathrm{d}$ is recommended to be at least $50 \mathrm{~cm}$ by the environmental bodies from United States. The hydraulic conductivity of the fine sand is given $2 \times 10-4 \mathrm{~m} / \mathrm{s}$. The depth of clearance above the sand layer is $10 \mathrm{~cm}$. 


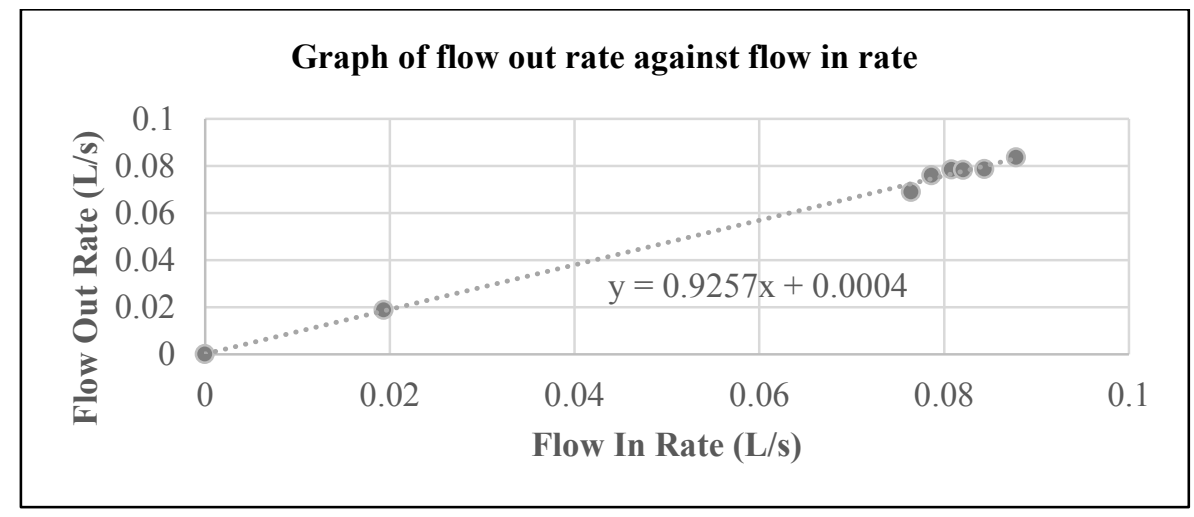

Fig. 5. Graph of flow out rate against flow in rate

$$
\begin{gathered}
\text { Qmax }=\text { k.A. }(\mathrm{h}+\mathrm{d}) / \mathrm{d} \\
=(2 \times 10-4)(\pi 0.212)[(0.1+0.5) / 0.5] \\
=3.325 \times 10-5 \mathrm{~m} 3 / \mathrm{s} \\
=119.70 \mathrm{~L} / \mathrm{h}
\end{gathered}
$$

Based on the calculated Qmax, the sand depth is designed to be $50 \mathrm{~cm}$. This is because the flow of water entering the sand filtration is lower than the maximum flow rate can be handled by the slow sand filtration system with $50 \mathrm{~cm}$ sand depth. Based on the experiments and calculation the final design of the system with collection tank is shown in Figure 6 and Figure 7. The collection tank is design to collect $1000 \mathrm{~L}$ of capacity.

Table 5. Flow rate entering the slow sand filtration and surface area of sand

\begin{tabular}{|c|c|c|c|c|c|}
\hline $\begin{array}{c}\text { No of } \\
\text { bedrooms }\end{array}$ & $\begin{array}{c}\text { Daily water } \\
\text { use (gal) }\end{array}$ & $\begin{array}{c}\text { Greywate } \\
\text { r flow } \\
\text { rate (L/h) }\end{array}$ & $\begin{array}{c}\text { Flow rate } \\
\text { entering the } \\
\text { sand filtration } \\
\text { (L/h) }\end{array}$ & $\begin{array}{c}\text { Surface Area } \\
\text { of Sand } \mathbf{( m}^{\mathbf{2}} \text { ) }\end{array}$ & $\begin{array}{c}\text { Radius } \\
\text { sand } \\
\text { surface } \\
\text { (cm) }\end{array}$ \\
\hline 1 or 2 & 225 & 35.49 & 32.85 & 0.08 & 16.17 \\
\hline 3 & 300 & 47.32 & 43.80 & 0.11 & 18.67 \\
\hline 4 & 375 & 59.15 & 54.76 & 0.14 & 20.87 \\
\hline
\end{tabular}




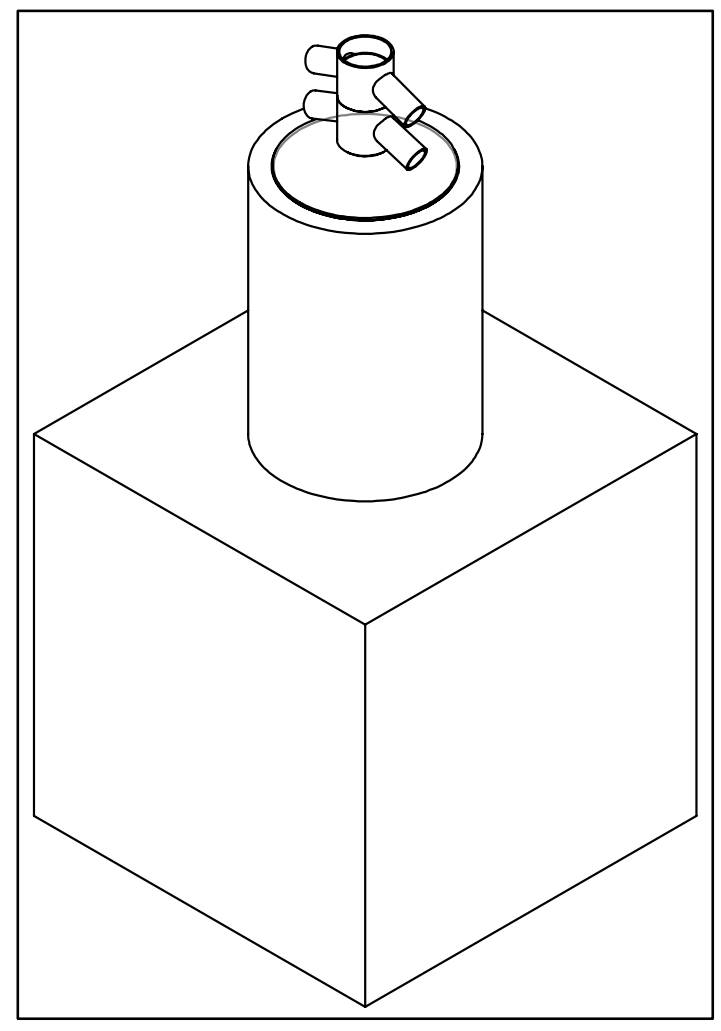

Fig. 6. 3D design of the system with the collection tank 


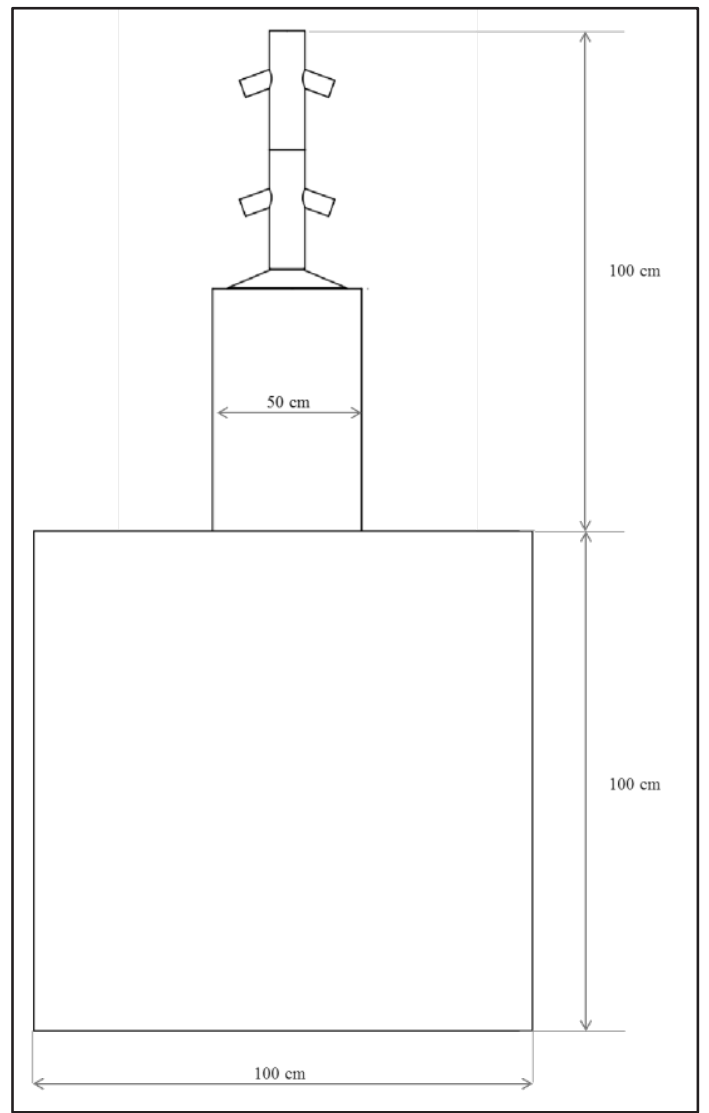

Fig. 7. Detailed design of the system with the collection tank

The design is evaluated by carrying out experiments to determine the COD, TSS and turbidity value of the treated water using the small-scaled prototype. The data collected are shown in Figure 8.

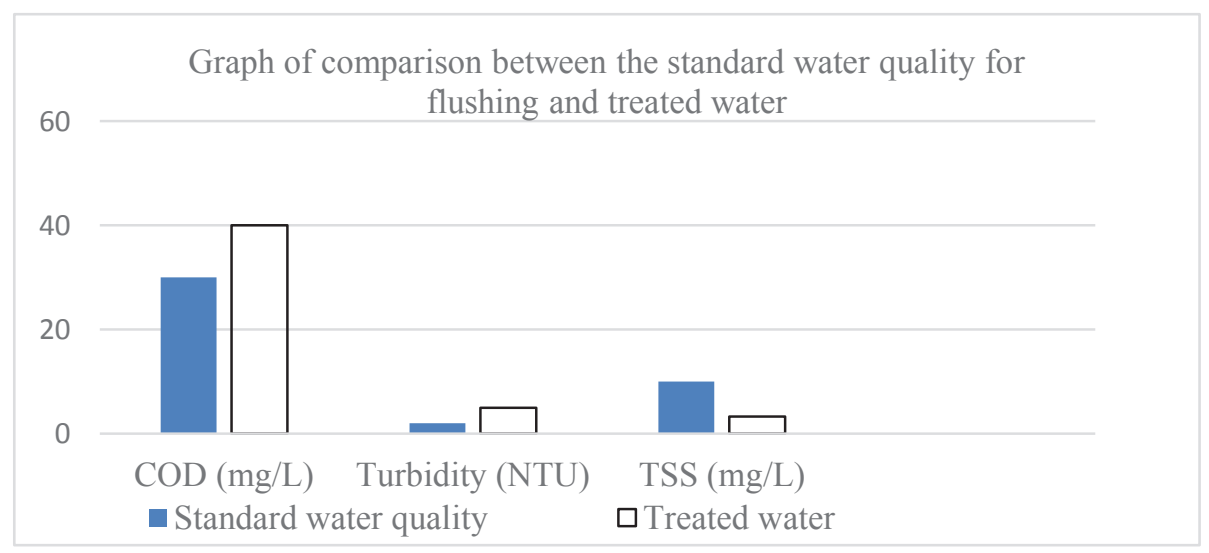

Fig. 8. Bar chart comparison for standard flushing water quality and treated water 
The turbidity of the treated water in this experiments is less than 5 NTU. The total suspended solid in the treated water is $3.33 \mathrm{mg} / \mathrm{L}$. The TSS value required for the toilet flushing water is less than $10 \mathrm{mg} / \mathrm{L}$. Therefore, the design fulfils the requirement for the TSS value. The COD of the treated water is $40 \mathrm{mg} / \mathrm{L}$. The required COD for the toilet flushing water is less than $30 \mathrm{mg} / \mathrm{L}$. The COD requirement was not able to fulfilled because of the small-scale prototype.

Based on the finalised design, the price to manufactured one complete filter system is estimated. The complete system includes the plastic filter chassis for the pre-treatment filter and slow sand filtration, filter sand, wire mesh, auto water pump and collection tank. The price for each product is obtained and the total cost is calculated as shown in Table 6 . The experiments to evaluate the performance of system by measuring the TSS, COD, and turbidity of the treated water are conducted using the prototype.

As can be seen in Table 6, the budget to manufacture one complete system using the design in this project is lower than cost of the existing greywater recycling package. The existing home scale greywater system in the market is a down-scaled of industry greywater recycling design. Therefore, the cost of this existing home scale greywater recycling package design is 8,100 USD. This design has high cost due to the technology that are used in this system. This system consists physical treatment using different size of mesh and membrane. Then, the biological treatment is carried out using the UV ray. The UV ray neutralises the microorganism in the water. The parts that cause the system to be expensive are the membrane, UV ray and pump. This design is relatively cheaper because this designs does not uses any membrane as the physical filtration and high performance pump for the water movement through the membrane. The membrane is replaced by the sand filtration which able to meet the same turbidity and pump is replaced by the gravitational force in the sand filtration. The UV ray is replaced by the sand filtration because the water and residue accumulated at the top of the sand layer forms biological reaction bed layer. The microorganisms are neutralised at top of the sand through biological treatment.

Table 6. List of price for the filtration system

\begin{tabular}{|c|c|c|c|}
\hline Product & Price & Quantity & Total (USD) \\
\hline Filter chassis & $25.80 \mathrm{USD} / \mathrm{kg}$ & 10.073 & 259.8834 \\
\hline Auto water pump & $133.43 \mathrm{USD}$ & 1 & 133.43 \\
\hline Filter fine sand & $2.41 \mathrm{USD} / \mathrm{kg}$ & 117 & 281.97 \\
\hline Gravel & $2.31 \mathrm{USD} / \mathrm{kg}$ & 80 & 184.8 \\
\hline $1000 \mathrm{~L}$ water tank & $425.55 \mathrm{USD}$ & 1 & 425.55 \\
\hline $1 \mathrm{~mm}$ wire mesh & $60 \mathrm{USD} / \mathrm{sheet}$ & 1 & 60 \\
\hline $0.5 \mathrm{~mm}$ wire mesh & $80 \mathrm{USD} / \mathrm{sheet}$ & 1 & 80 \\
\hline \multicolumn{2}{|l}{ Total Cost (USD) } & $\mathbf{1 4 2 5 . 6 3}$ \\
\hline
\end{tabular}

Therefore, the optimisation of the design involves the cost of the system. The recycling package is designed at relatively lower cost with same function and requirement. This low cost provides more chances for the customer to buy this product. This can increase the attention and business value of greywater recycling package. 


\section{Conclusion}

The greywater treatment package is successfully designed within proposed budget The design of the system is within $6 \mathrm{~m}^{3}$ including the collection tank. The greywater treatment package contains the pre-treatment filter, slow sand filtration and collection tank. The effect of the pre-treatment stage on the flow entering the slow sand filtration is studied to design the slow sand filtration. Based on the experiments, the slow sand filtration is designed based on the volumetric flow rate and Darcy's law. The material budget of a complete system is lower than the existing home scale greywater recycling system. This design is able to treat greywater to meet the standard water quality of toilet flushing.

\section{References}

[1] K. Bani-melhem and E. Smith, Chem. Eng. Journal., 198-199, 201-210, (2012).

[2] M. S. Fountoulakis, N. Markakis, I. Petousi, and T. Manios, Sci. Total Environ. Journal, 551-552, 706-711, (2016).

[3] J. A. Peeples, Wastewater Use Agric., II, 119-131, (2006).

[4] B. Je, A. Laine, S. Parsons, T. Stephenson, and S. Judd, Journal of Elsevier, 1, 1999, (2000).

[5] F. Li, K. Wichmann, and R. Otterpohl, Sci. Total Environ. Journal, 407, 11,. 34393449, (2009).

[6] B. A. Mittal, "Biological Wastewater Treatment," FullTide Corporation, 2-9, (2011).

[7] Y. Dunets, Siobhan; Zheng, "Slow sand filtration," Greenh. Nurs. Watery, (2011).

[8] W. T. Course, Sci. Total Environ. Journal, 1-2, (2012).

[9] B. Lesikar, R. Melton, D. Smith, and C. O. Neill, "AgriLife Communications and marketing, 3-08, (2003).

[10] Centre for Affordable Water TEchnilogy, "What is the minimum depth of filtration sand, underdrain gravel and separating gravel? (particularly." Cisco Foundation, 1, (2017).

[11] Members of WQA, "Residential Water Reuse Fact Sheet," Water Quality Association, 1-5, (2013).

[12] T. Bruursema, Plumbing Systems \& Design Magazine, 15-22, (2011).

[13] American Water Standard, "NSF/ANSI Standard 350 For Water Reuse Treatment Systems," (2011).

[14] V. Lazarova, Milestones in Water Reuse. The International Water Association, (2013).

[15] Chicago School Network, "Turbidity," Turbid. Test Procedure., 1-2, (2013).

[16] Y.-C. Kim, S. Sasaki, K. Yano, K. Ikebukuro, K. Hashimoto, and I. Karube, Anal. Chim. Acta, 432, 1, 59-66, (2001).

[17] J. Chen, J. Zhang, Y. Xian, X. Ying, M. Liu, and L. Jin, Water Res.Journal, 39, 7, 1340-1346, (2005). 